\title{
La crisis del sistema trilateral y América Latina
}

La formación del sistema trilateral (Estados Unidos, Europa Occidental-Japón) constituye el proceso dominante del desarrollo contemporáneo de la economía mundial. En este trabajo se procura trazar, a grandes rasgos, la evolución del sistema, su crisis actual y la posición latinoamericana en el actual contexto internacional.

Las turbulencias en los mercados cambiarios y los desequilibrios en los pagos internacionales se suman ahora a un cuadro de dificultades reales de alto desempleo, lento crecimiento y persistentes presiones inflacionarias en los paises que integran el sistema trilateral. Estas tendencias están generando nuevos problemas y perspectivas distintas en las transacciones entre los paises industriales, que constituyen, descle el fin de la Segunda Guerra Mundial, el campo dominante del comercio $y$ el movimiento internacional de capitales. Asimismo, comprometen otras áreas vitales de las relaciones internacionales, tales como la posición del dólar como principal activo de reserva y fuente de liquidez, las políticas comerciales y las relaciones con los países en desarrollo, incluyendo los miembros de la oper. Las convergencias y conflictos que nutren los vínculos dentro del bloque trilateral, adquieren nuevas dimensiones y perspectivas en el marco de una situación crítica que trascienda el plano financiero y monetario. Es decir, que abarca la incapacidad de compatibilizar un comportamiento ordenado de los precios y' la distribución del ingreso con el crecimiento sosteniclo de la proclucción y el empleo. Si esa incapacidad no se elimina, parece difícil que los países centrales puedan enfrentar con exito los conflictos en sus relaciones recíprocas, las turbulencias dei sistema monetario intemacional y los desafíos que, descle el Tercer Mundo, se plantean a su posición hegemónica. El comportamiento futuro del sistema munclial está decisivamente condicionado por la lucidez y eficacia con que los paises industriales enfrenten sus principales problemas.

El desempeño de las economías centrales continuard afectando el desarrollo intemo y lá inserción internacional de los paises latinoamericanos. Pero, a diferencia del pasado, varios países del área no son ya agentes pasivos en el escenario internacional, con muy escasa capaciclad de maniobra frente a las tendencias planteadas en el sistema mundial. Dificilmente los países latinoamericanos podrán in- 
fluir, en el futuro previsible, el comportamiento de ese sistema. Su posición es y seguirá siendo marginal. Ni siquiera Brasil podría jugar, por lo menos a mediano plazo, un papel protagónico en los acontecimientos internacionales. Pero, en cambio, se ha fortalecido la libertad de maniobra para condicionar las relaciones con el mundo externo y vincular positivamente el proceso de desarrollo a las transformaciones del sistema mundial. En resumen, los países latinoamericanos pesan y seguirán pesando poco en el sistema mundial, pero amplióse su libertad de maniobra internacional. El desarrollo registrado en las economías principales del área y la dispersión del poder económico entre varios grandes centros, han generado una situación paradojal: relaciones más complejas con el contexto internacional y mayor autonomía potencial frente al resto del mundo. En este encuadre, el fortalecimiento de los vínculos intralatinoamericanos continúa siendo una opción abierta a cada uno de los paises del área para profundizar su desarrollo y aumentar su autonomía en la conducción de sus relaciones internacionales. El comportamiento del sistema mundial afectará la inserción externa de cada país y el ámbito de posibilidades de la interdependencia latinoamericana.

Con vistas a explorar las cuestiones así planteadas, el lector encontrará, en este trabajo, un primer apartado que describe el tránsito desde la abrumadora hegemonia norteamer.cana, en la temprana postguerra, hacia el sistema trilateral. Los rasgos dominantes de la crisis actual del sistema son tratados en el apartado siguientc. Por último, se procura insertar las relaciones Norte-Sur en el actual contexto internacional y explicitar las razones, según las cuales la América Latina cuenta hoy con una libertad de iniciativa y libertad de maniobra externas sin precedentes históricos.

\section{DE LA HEGEMONIA NORTEAMERICANA IAL SISTEMA TRILATERAL}

Desde el fin de la Segunda Guerra Mundial hasta principios de la década de 1970, pueden identificarse dos períodos principales en el funcionamiento del sistema económico mundial 1 . El primero abarca los años de la abrumadora hegemonía norteamericana. El segundo, los del predominio del bloque trilateral (Estados Unidos-Europa Occidental-Japón). En este último, la hegemonia de los Estados Unidos está condicionada por sus relaciones de interdependencia con un grupo de economias de gran poder económico. El bloque trilateral se fue gestando progresivamente durante el primer período y es el re-

I Vista la escasa gravitación de los países socialistas dentro del orden económico mundial, es legitimo concentrar el análisis en el funcionamiento de los pafses capitalistas y la periferia asociada al sistema liderado por aquéllos. Esta es la acepcion restringida a las expresiones sistema mundial, orden internacional y similares que se emplean en el texto. 
sultado directo, entre otras cosas, de la forma en que los Estados Un:dos ejercieron su posición hegemónica inicial y lideraron la recuperación económica mundial de postguerra.

Después de la guerra, la producción de los Estados Unidos de bienes y servicios representaba más del $60 \%$ de la producción agregada del mundo capitalista industrializado, sus reservas de oro superaban el $80 \%$ de las mundiales y sus exportaciones equivalían a casi $1 / 3$ de las provenientes desde los países industriales. En la segunda mitad de la década de 1940, los Estados Unidos registraban un fuerte superávit de comercio y otros pagos corrientes frente a los otros paises industriales $y^{\prime}$ el resto del mundo. Dada la dimensión de la economía norteamericana, esta abrumadora gravitación en el sistema mundial no tenia, como contrapartida, una influencia similar del sector externo dentro de sus propias fronteras. Esto conferia a la economía norteamericana un notable grado de autonomía en la conducción de sus relaciones externas, esto es, Ia posibilidad de manejarlas con independencia de la administración de la liquidez y demanda internas, la producción y el empleo. Esta autonomía fue reforzada por ser los Estados Unidos el país emisor del principal activo de reserva internacional $y$, consecuentemente, por su facultad de financiar el déficit de pagos externos, hasta bien entrada la década de 1960, sin pérdidas fundamentales de sus reservas de oro.

La asistencia económica norteamericana bajo el Plan Marshall y otros cauces jugó un papel importante en la reconstrucción cle postguerra de los principales países europeos y Japón. Pero, mucho más que esta ayuda directa, el factor dominante de la expansión econó. mica del sistema fue el comportamiento de las relaciones comerciales y financieras de los Estados Unidos con el resto de los países industriales. El tradicional superávit comercial de los Estados Unidos fue más que compensado por los gastos para financiar su influencia política y militar en el resto del mundo y las crecientes inversiones de las corporaciones norteamericanas en el exterior. El persistente déf:cit del balance de pagos, fuc principalmente financiado con un aumento de las tenencias de dólares en el resto del mundo. El consecuente aumento de reservas internacionales en los otros países desarrollados, facilitó la expansión de sus gastos y liquidez interna. Permitía, simultáneamente, eliminar las restricciones a los cambios $y$ al comercio, heredadas de la temprana postguerra. Hacia fines de la década de 1950, se había consumado la eliminación de las restricciones cambiarias de las principales monedas europeas y del yen y la reducción de aranceles y otras restricciones al comercio, dentro de las negociaciones en el seno del Gatr.

La recuperación de Europa y Japón y la sobrevaluación del dólar, fueron debilitando la posición competitiva de los Estados Unidos. De este modo, el deterioro progresivo del superávit comercial se 
agregó al deficit en la cuenta de capital y a los gastos militares en el exterior. De todos modos, la reducida gravitación del sector externo, y el financiamiento del déficit a través del endeudamiento a corto plazo, permitieron tolerar el deterioro del balance de pagos sin efectos sensibles sobre la demanda agregacta, la producción y el empleo.

Este comportamiento de la economía norteamericana jugó un papel decisivo en la recuperación económica del mundo industrializado y en la vertiginosa expansión del comercio internacional. La participación norteamericana en este proceso se realizó, predominantemente, a través de sus grandes corporaciones industriales y de sus principales bancos. La transnacionalización fue el rasgo dominante del crecimiento de las grandes empresas industriales y financieras de los Estados Unidos. Este proceso se orientó, fundamentalmente, hacia otros países industriales y contribuyó a profundizar los vínculos dentro del mundo desarrollado.

Estas tendencias provocaron cambios profundos en la estructura del balance de pagos norteamericano. Junto al deterioro progresivo del balance comercial y el déficit en la cuenta de capital, apareció, como factor parcialmente compensador, el creciente ingreso de utilidades e intereses de las inversiones norteamericanas en el exterior. En otros términos, el deterioro de la posición norteamericana en el comercio de bienes y el deficit en cuenta de capital fue compensado, en parte, por el superácit en ciertos servicios - como las ventas de tecnologia- y los servicios de capital norteamericano inverticlo en el resto del mundo.

El comportamiento de la economía norteamericana, la expansión de sus corporaciones y. el rápido crecimiento de Europa y. Japón, impulsaron un vertiginoso desarrollo de las transacciones comerciales y del movimiento de capitales entre países industriales. Se constituyó así, en pocos años, un macromercado que abarca a las principales economías industriales y dentro del cual se registran las principales corrientes de intercambio. La división internacional del trabajo en el seno de ese macromercado, constituye el hecho dominante en la experiencia económica de postguerra. La antigua relación centroperiferia y la tradicional división internacional del trabajo entre países industriales y economias de producción primaria, fue sustituida, como núcleo dinámico del comercio y del movimiento internacional de capitales, por aquella relación entre las mismas economías industriales. El comercio entre los países que hoy integran la OECD, representaba, en la década de 1930 , el $40 \%$ del comercio mundial. La proporción aumentó al $47 \%$ en 1960 y al $57 \%$ en 1970 . Entre 1948 y 1970 , el intercambio dentro del bloque de paises industriales aumentó del $64 \%$ al $77 \%$ del comercio exterior total de esos países. En. el caso de los Estados Unidos, el aumento fue aun más acentuado: 
del $41 \%$ al $73 \%$. La división internacional del trabajo dentro del mundo desarrollado se registró, fundamentalmente, en la producción. industrial y la participación del intercambio de manufacturas entre los paises industrializados, dentro del comercio mundial, pasó de alrededor del $20 \%$ en la clécada de 1930 , al $31 \%$ en 1960 y al $42 \%$ en 1970. En cambio, el intercambio centro-periferia perdió rápidamente importancia: en la década de 1930 representaba alrededor deì $40 \%$ del comercio mundial, en 1960 el $32 \%$ y en 1970 el $27 \%$. Particuiarmente notable fue el deterioro de la significación latinoamericana en el comercio exterior de los Estados Unidos. Dentro del total de las importaciones norteamericanas, las de origen latinoamericano disminuyeron su participación, entre 1948 y 1970 , del $35 \%$ al $11 \%$.

En estos procesos influyeron un conjunto de factores vinculados al progreso técnico y los cambios en la composición de la demanda. La concentración del progreso técnico en industrias de alta concentración de capital, generadoras de economías de escala y susceptibles de especialización a escala internacional, impulsaron el desarrollo industrial en los sectores más complejos. Simultáneamente, las actividades en expansión se integraron en el contexto del macromercado capitalista. Las corporaciones norteamericanas jugaron un papel decisivo en esta integración de las economías industriales y en la difusión del progreso técnico. Inclusive en Japón, donde se restringió severamente el acceso de inversiones privadas directas del exterior, la absorción de tecnologia de los Estados Unidos contribuyó al rápido desarrollo industrial.

La baja elasticidad-ingreso de la demanda de productos primarios fue el otro factor decisivo que contribuyó a modificar sustancialmente la composición del comercio internacional y la participación, en el mismo, de los países industrializados y de las economías en desarrollo. La pérdida de participación de las materias primas y alimentos en el gasto total de las economías avianzadas, la sustituciónide productos naturales por productos sintéticos, la reducción del-insumo de materiales por unidad de producto final y otros factores, provocaron un crecimiento relativamente lento de la demanda de productos primarios. A esto se agregó el protecciónismo dé la producción primaria doméstica de los principalés países, como en el caso de la política agricola de la Comunidad Económica Europea. De hecho, el intercambio de productos primarios entre países industriales pasó a representar la proporción mayor dentro del comercio mundial de alimentos y materias primas. Sólo algunos minerales y, sobre todo, el petróleo, escaparon a estas tendencias del comercio mundial de pastguerra. EI resultado fue la rápida pérdida de importancia de los productos primarios en el conjunto del comercio mundial y la disminución de la participación de los países de la periferia en el 
mismo. Esta participación declinó dè $30 \%$ a fines de la década de 1940 , al $21 \%$ en 1960 y al $17 \%$ en 1970 .

La formación del macromercado y la rápida expansión de las transacciones en su seno actuaron como un poderoso factor de estímulo, sobre todo, fuera de los Estados Unidos. En una economía continental como la norteamericana, los factores internos siguieron determinando el ritmo y la orientación de su desarrollo. Pero, en el resto del mundo industrializado, el comercio exterior comprometió áreas crecientes del sistema económico, particularmente en las industrias dinámicas de rápido ritmo de expansión y elevado crecimiento de la productividad.

Un conjunto de fuerzas determinó que el crecimiento de la economía norteamericana, hasta prácticamente fines de la década de 1960, fuera menos intenso que en Alemania, Japón y otros países industriales. En primer lugar, la rápida reconstrucción de los paises afectados por la guerra permitió eliminar aquella parte de la preponderancia norteamericana que se basaba en la destrucción del poder económico de otros países industriales. En seguida, el rezago industrial y tecnológico de estos países abrió oportunidades nuevas que en los Estados Unidos estaban ya cubiertas. Además, las economias de escala y especialización impactaron más intensamente en Europa y Japón que en los Estados Unidos. En éstos, la existencia: de un mercado continental y los avances ya registrados en la formación de grandes empresas y conglomerados, anticiparon los incrementos de productividad que en aquellos otros países recién se lograron después de la guerra. Por la misma razón, la apertura externa fue más importante en términos de impulso a la productividad para los países europeos y Japón que para los Estados Unidos, los cuales con su mercado continental habian consumado ya una elevada especialización $y$ división interna del trabajo. Por otra parte, la sobrevaluación del dólar deterioró la posición competitiva de los Estados Unidos. Como se volverá a insistir más adelante, este deterioro no fue consecuencia de errores en el manejo del proceso de ajuste entre los países industriales. Era, por el contrario; una condición necesaria para impulsar la formación del bloque de paises industriales y expandir, dentro del mismo, la acumulación de capital, la producción $y$ el empleo.

El menor ritmo de crecimienta de los Estados Unidos, con respecto a Alemania, Japón y otros países industriales, erosionó progresivamente su ábrumadora posición hegemónica inicial. Hacia fines de la década de 1960, la producción norteamericana representaba alrededor del $47 \%$ del total de la producción agregada clel mundo industrializado, frente a más del $60 \%$, veinte años antes. Los Estados Unidos mantuvieron una gravitación sustancial en el macromercado, pero el peso creciente de Alemania, Japón y otros países in- 
dustriales, modificaron, progresivamente, las posiciones relativas y las relaciones de poder dentro del bloque. Además, los Estados Uniclos fueron perdiendo participación en el comercio internacional. Otros paises industriales adquirieron un mayor peso relativo en las transacciones comerciales y sus propias corporaciones comenzaron a participar en el movimiento internacional de capitales, quebrando el predominio casi absoluto de las empresas norteamericanas en la temprana postguerra.

E1 sistema monetario internacional operó con considerable eficacia en todo este periodo y facilitó el desarrollo de las fuerzas expansivas de la economía mundial ${ }^{2}$. El Acuerdo de Bretton Woods preveía un régimen de paridades fijas pero ajustables, el cual, junto a las políticas de ajuste interno, permitiría un comportamiento ordenado de los pagos y de la liquidez internacionales. Sin embargo, la clave del proceso de expansión descansó en el déficit continuado del balance de pagos norteamericano $y$ en la rápicla expansión de las reservas de dólares en el resto del mundo. El dólar sustituyó rápidamente al oro como principal actiro de reserva fuera de los Estados Unidos y como fuente de expansión de la liquidez internacional. El déficit norteamericano y el superávit de Alemania, Japón y otros países industriales, implicaban un clesajuste básico en el proceso de ajuste intemacional. Pero era precisamente ese desajuste el que operaba como impulsor del crecimiento del macromercado, de la producción y el empleo a escala internacional. No eran las rigideces del mecanismo de ajuste de paridades previsto en Bretton Woods, ni la supuesta insensatez de las políticas fiscales y monetarias de los principales países, los responsables de los desequilibrios en los pagos internacionales.

El comportamiento del balance de pagos de los Estados Unidos jugó, a escala internacional, el mismo papel que la banca central cuando financia, en una economía nacional, parte del gasto con expansión monetaria. En los países industriales, la política fiscal y' monetaria se regía por los criterios keynesianos de formación de la demanda agregada a través del financiamiento deficitario, para alcanzar el pleno empleo. Dentro del grupo de paises industriales, el déficit del balance de pagos de los Estados Uniclos y el aumento de su endeudamiento a corto plazo cumplia exactamente el mismo papel de expansión de la oferta monetaria y la demanda agregada. Impiicaba, de hecho, el triunfo del keynesianismo a escala internacional.

Los banqueros centrales y los expertos monetarios, que suelen confundir las apariencias con la realidad, podían creer que los problemas radicaban en las sutilezas de las reglas de ajuste. Pero eran

2 Véase del autor, Economia Internacional contemporánea. Fondo de Cultura Económ:ca, México, 1976. 
decisiones explícitas o implícitas de aquellos países las que generaron tales desequilibrios.

Todos los participantes de este proceso se beneficiaron con él. Los Estados Unidos porque, como país emisor del principal activo de reserva internacional, financió la expansión de sus empresas y su influencia política militar, sin una transferencia real de recursos. EI resto de los países industriales, porque recibia, por esta vía, un impulso a su demanda agregada y a sus sreservas internacionales que actuaban como poderosos agentes de expansión.

El desarrollo de los euromercados fue una de las consecuencias más notables de la expansión de la liquidez internacional en manos de particulares y de las autoridades monetarias. Las actividades de las corporaciones transnacionales generaron corrientes comerciales $y^{\prime}$ financieras, dentro de cada conglomerado, que adquirieron notoria gravitación en el funcionamiento de los mercados. La formación de un gran poder financiero, fuera del control de las autoridades monetarias de cada país, generó una fuente de expansión secundaria de la liquidez internacional que contribuyó a la expansión de las transacciones internacionales, intensificó los movimientos especulativos de capitales y, según algunos analistas, contribuyó a sentar las bases del posterior proceso inflacionario. La intemacionalización de la banca y, sobre todo, de los principales bancos norteamericanos, fue uno de los rasgos principales del proceso de integración y transnacionalización del macromercado y de la vinculación al mismo de la periferia tercermundista e, inclusive, de los países socialistas.

Estas tendencias operaron prácticamente sin tropiezos en la segunda mitad de la década del 40 y en toda la del 50. Los resultados fueron un crecimiento de la producción, el comercio y el movimiento internacional de capitales, sin precedentes en la historia económica mundial. En este contexto, se afianzaron las politicas orientadas a enfatizar el pleno empleo como objetivo dominante de la política económica, creció significativamente la gravitación del sector público y aumentaron los salarios reales y el bienestar en el mundo industrializado. Vistos en perspectiva, los resultados de la política norteamericana de postguerra fueron realmente espectaculares. Alcanzó los objetivos fundamentales que se propuso en términos de fortalecimiento e interdependencia de los países inclustriales y la ráp:da expansión de las grandes empresas norteamericanas en el resto del mundo. Esto facilitó decisivamente la gestión de su estrategia politica y militar frente a la Unión Soviética. El conflicto de Vietnam fue la única derrota grave de la politica norteamericana y ocurrió en un área marginal a sus intereses fundamentales dentro del nuevo sistema de postguerra.

La periferia de los países centrales permaneció al margen de las nuevas conientes expansivas de la economia internacional. Quedó 
atrapada en un circulo vicioso: la especialización en la exportación de productos primarios y el rápido crecimiento de su demanda de manufacturas. Las consecuencias fueron una declinación del peso relativo del comercio exterior dentro de la actividad económica y un crónico desequilibrio externo. Este proceso, que refleja predominantemente la experiencia de la mayor parte de América Latina, contribuyó a promover la sustitución de importaciones y la industrialización. A partir de aquí se crearon nuevos vínculos con el mundo industrializado por la expansión de las inversiones privadas directas en el sector industrial, la transferencia de tecnología $y$ relar ciones financieras más complejas. In buena medida, la periferia creció al margen de la expansión del macromercado capitalista, generando, con éste, nuevos vínculos más complejos que constituyeron, a veces, factores de impulso al crecimiento y, las más, obstáculos adicionales al desarrollo acclerado, integrado y autónomo.

En el curso de la década de 1960 comenzaron a acrecentarse las tensiones dentro del régimen hegemónico norteamericano. Concluida la reconstrucción de los países europeos y Japón y consolidado su desarrolio y posición financicra internacional, comenzaron a surgir resistencias al continuado financiamiento de la expansión norteamericana mediante el aumento de las tenencias de dólares en el resto deI mundo. Se trataba, fundamentalmente, de un replanteo de las relaciones de poder dentro del macromercado, una vez que el apoyo norteamericano dejó de ser necesario en el proceso de reconstrucción y despegue. A partir de aquí, pasó a cuestionarse el manejo de las relaciones políticas y militares de los Estados Uniclos frente al resto del mundo y la expansión internacional de las corporaciones norteamericanas. EI conflicto político fue planteado, en primer lugar, pnr Francia. Simultáneamente, los desequilibrios acumulativos y crecientes en los pagos internacionales, comenzaron a generar turbulenc:as cada vez más severas en los mercados cambiarios. Por un lado, la conversión, por Francia y otros países, de parte de sus tenencias de dólares contra oro de la Tesorería norteamericana, disminuyó rápidamente el respaldo del endeudamiento externo de corto plazo de los Estados Unidos. Por otro, la sobrevaluación del dólar y la enorme masa de capitales líquidos existentes en los mercados financieros internacionales, generaron crecientes corrientes especulativas contra el dólar, anticipatorias de esperados reajustes en su paridad. Desde la primera crisis en el mercado del oro de Londres, en 1960, hasta principios de la década de 1970, los mercados cambiarios estuvieron sujetos a tensiones, a veces tan insoportables, que llevaron a su cierre transitorio.

De este modo, ei proceso de ajuste del desequilibrio de pagos de los principales países, pasó a constituirse en el tema dominante del debate económico internacional. Simultáneamente, el ahora deseado 
$y$ esperado equilibrio en el balance de pagos de los Estados Unidos, sumado a la rápida pérdida de importancia del oro como fuente de expansión de la liquidez internacional, promovió la búsqueda de fuentes de liquidez alternativas al dólar y al oro. Los debates en el seno del FMr. sobre la reforma del sistema monetario internacional, tuvieron como primer fruto la creación de los derechos especiales de giro en 1967.

Durante la década de 1960, resultaron infructuosos todos los esfuerzos por mantener las reglas del jucgo preestablecidas. La desvinculación del mercado del oro de las tenencias oficiales del metal. los swaps y acuerclos entre bancos centrales para sostener al dólar y otras monedas en dificultades y, aun, la moderada revaluación del marco, el yen y otras monedas superavitarias, fueron totalmente insuficientes para restablecer el equilibrio en los pagos internacionales, un comportamiento ordenado en los mercados cambiarios y el crecimiento moderado de la liquidez internacional. Los desequil:brios siguieron y el intento norteamericano de apelar a la tasa de interés para revertir el flujo de capitales de corto plazo, demostró tener un costo intolerable en términos de nivel de la actividad económica interna y el empleo. Los Estados Unidos afirmaron en todo el período. como objetivo búsico de su política, el mantenimiento de la paridad y la convertibilidad del clólar. Esto introdujo una rigidez extrema en un sistema, dentro del cual los desequilibrios de pagos y los movimientos especulativos de capitales eran exageradamente altos.

En este contexto, el debate entre los principales países se centró en el problema fundamental: cómo eliminar el déficit del balance de pagos norteamericano y los supcrávic de otros países, en primer lugar, de Alemania y Japón. En torno de esta polémica se desarrollaron, en la década del 60, dos líneas principales de argumentación. Una de ellas, liderada por Francia, que postulaba la necesidad de que los Estados Unidos equilibraran su cuenta cle capital y redujeran sus gastos de finalidad política y militar en el resto del mundo. Esta postura enfatizaba el hecho que el balance comercial de los Estados Unidos registraba todavía superávit y que los ingresos, en concepto de utilidades de las inversiones norteamericanas en el exterior, eran cada vez más grandes. Era en los otros rubros del balance de pagos en donde debía restablecerse el equilibrio. La posición norteamericana enfatizaba, en cambio, el ajuste de pagos vía el aumento del superávit comercial de los Estados Unidos, fuertemente restringido, se argumentaba, por las politicas proteccionistas de los otros países industriales - como en el caso de la política agrícola de la Comunidad Económica Europea- y la resistencia a revaluar sus monedas vis a vis el dólar. Estas desinteligencias siguieron hasta agosto de 197. Entonces, las medidas del Presidente Nixon provocaron un 
cambio radical en Ia postura norteamericana de clefensa de la convertibilidad y la paridad del dólar, forzando la adopción de cambios sustanciales en las reglas del juego preexistentes.

Cabe recordar que la polémica y los conflictos entre los países industriales no comprometieron las convergencias e interdependencias gestadas en la postguerra. Fueron, y siguen siendo, problemas entre socios que comparten intereses fundamentales. Sólo que, en el marco de la nueva situación de dispersión del poder en el seno del sistema trilateral, los conflictos adquirieron una repercusión desconocida cuando los Estados Unidos, con su abrumadora posición hegemónica inicial, los transaba por si solos y, cabe recorclar, por lo general, para beneficio de todos los participantes del sistema.

En todo este proceso la periferia siguió siendo un espectador pasivo. Los debates sobre la reforma del sistema monetario internacional y los acuerdos de los principales países en el seno del Grupo de los $10 \mathrm{y}$ de la $\mathrm{OECD}$, sólo prestaron una atención marginal a los problemas enfrentados por los países en desarrollo. La "ay'uda externa", las preferencias generalizadas y otros esquemas fueron meros paliativos intrascendentes, destinados a sosegar la creciente presión politica ejercida clesde la periferia del sistema.

\section{LA GRISIS DEL SISTEMA TRILATERAL}

A principios de la década de 1970 comenzaron a agudizarse las tensiones que se habian venido gestando en el seno del sistema trilateral. Por una purte, se agravaron los desequilibrios en los pagos internacionales de los principales países industriales. Esto introdujo tensiones insoportables en el funcionamiento del sistema monetario internacional establecido en Bretton Woods. Por otra parte, el fuerte aumento de los precios del petróleo, a fines de 1979, introdujo un nuevo e importante factor de desequilibrio en los pagos internacionales. Pero mucho más que estos factores, la crisis clel sistema trilateral se vincula a la intensificación de las presiones inflacionarias en los paises clesarrollados y a la incapacidad de compatibilizar el pleno empico con una estabiliclad razonable de precios. Las políticas keynesianas, predominantes desde el fin de la Segunda Gucrra Munclial, tropezaron, a partir de principios de la década de 1970, con graves problemas. La tentativa de regular la demanda agregada a través de la política fiscal y monetaria, con vistas a mantener el pleno empleo, generó crecientes presiones inflacionarias. Se sumú a esto la presencia de una serie de factores circunstanciales y, de algún modo, exógenos al sistema, que agravó el alza de precios. El rápido aumento de las cotizaciones de ciertos materiales industriales, algunas escaseces de la oferta en productos críticos y el fracaso de la producción 
agrícola en varios países, provocaron inesperadas alzas de precios en $1972 \mathrm{y}$ 1973. Al final de este último año, los precios del petróleo se cuadruplicaron y este factor, por si solo, representó un significativo aumento del nivel de precios en los paises industriales.

Frente a los nuevos problemas, las políticas económicas de postguerra fueron crecientemente cuestionadas y la ortodoxia neoclasica y monetarista comenzó a adquirir gravitación creciente en la gestación de lat política económica de los principales paises. El control de la inflación pasó a constituirse en el objetivo dominante, aun a costa del crecimiento y del nivel de empleo. Hacia la misma época, se difundieron, en el mundo industriatizado, algunos estudios que denunciaban la existencia de limites materrales al desarrollo a largo plazo de la economía mundial, debido al supuesto agotamiento de los recursos naturales no renovables y a la contaminación del medio ambiente. Estos enfoques parecieron avalados por el súbito aumento de los precios del petróleo y de otros productos básicos y generaron propuestas para trenar el desarrollo y aun alcanzar un crecimiento cero. En este contexto, la presión demográfica en ciertas áreas del Tercer Nundo y la extrapolación de las tendencias del crecimiento de la población, estimularon la formación de visiones cataclísmicas sobre el futuro de la humanidad. Sin embargo, los éxitos alcanzados en las politicas demográficas en varios paises en desarrollo, el reconocimiento del impacto de la mejora de los niveles de vida como factor regulador del crecimiento demográfico y una apreciación más realista sobre la disponibilidad de recursos naturales no renovables y los riesgos de la contaminación, tendieron, hacia mediados de la década de 1970 , a despejar el fatalismo de aquelios enfoques. Sobre todo, en los países desarrollados, frente a la gravedad de los problenas del receso, el desempleo y la inflación, disminuyó el interés por visiones prospectivas de largo plazo, sobre cuya confiabilidad, además, aumentaron las dudas.

Hasta principios de la década de 1970, las tensiones dentro del sistema trilateral y los desequilibrios de pagos se enfrentaban dentro de un marco de expansión de la producción, el empleo y el comercio internacional. A partir del receso de $1974-75$, esas tensiones y desequilibrios se registran en el marco de un crecimiento lento, alto desempleo y persistentes presiones inflacionarias. Consecuentemente, el proceso de ajuste de los desequilibrios de pagos internacionales se ha hecho más difícil $y$, to que es más grave, han surgido demandas proteccionistas que amenazan con derrumbar el orden dentro del cual se ha gestado $y$ ' expandido el sistema macrocapitalista de postguerra. Más aun, en este contexto, el sistema tiene menos capacidad de asimilar los cambios en la estructura de la producción y de los pagos externos de sus principales miembros $y$, en primer lugar, de los Estados Unidos. Consecuencia de estos hechos ha sido una mar- 
cada inestabilidad en los mercados cambiarios y en las cotizaciones del dólar y las otras monedas principales del sistema. Esto ha contribuido a agravar las tensiones y a dificultar el proceso de ajuste.

Por otra parte, el sistema trilateral enfrenta, en el curso de la década de 1970 , nuevos desafios gestados en su periferia. E1 más importante fue, descle luego, el incremento de los precios del petróleo. Pero el desafío es más amplio y se refleja en la propuesta de renovar el orden económico internacional y revisar el esquema tradicional de relaciones centro-periferia. Aunque estas relaciones son marginales para los intereses fundamentales del sistema trilateral, no dejan de agravar las tensiones que el mismo soporta. De este modo, las relaciones con el Tercer Mundo ocupan ahora, aunque todavía más en un plano declarativo que real, una posición más significativa en las preocupaciones de los principales países industriales.

La gravedad de la situación del sistema trilateral radica en que no es una simple crisis de pagos internacionales y de ajuste de los desequilibrios monetarios. Abarca ahora el plano real, es decir, la dinámica misma de la distribución del ingreso, la acumulación, el crecimiento $y$ el empleo en el mundo industrializado. $Y$, consecuentemente, das bases sobre las cuales se asentó la expansión de las relaciones económicas internacionales en las últimas tres décadas. De hecho, no parece posible que los países industriales pucdan dar respuesta eficaz a los problemas de las relaciones económicas internacionales sin encontrar, simultáneamente, nuevas bases para reanudar un crecimiento sostenido de la acumulación, la producción y el empleo. Esto implica encontrar soluciones válidas para enfrentar los conflictos en la distribución del poder y del ingreso en las economías centrales; conflictos que constituyen el núcleo de sus problemas actuales. En relación a la política económica, implica encontrar nuevos criterios que superen los límites del keynesinnismo y, por cierto, de la ortodoxia neoclásica y monetarista, cuyas consecuencias son extremadamente costosas. Costosas en términos de nivel de precios, producción y empleo y, además, riesgosas para la supervivencia del sistema liberal de comercio $y^{t}$ pagos, dentro del cual se ha gestado y expandiclo el sistema trilateral, incluyendo la transnacionalización de das grandes corporaciones de los principales países.

En las consideraciones siguientes se procura identificar Ios rasgos dominantes de la crisis del sistema trilateral.

\section{Agudización de los desequilibrios de pagos y los nuevos precios del petróleo}

- A comienzos de la década de 1970 se agudizaron los desequilibr:os de pagos que habian alimentado las tensiones del sistema moneta- 
rio internacional desde fines de la década de 1950. El cléficit norteamericano alcanzó proporciones descomunales en 1971. Registróse, ese año, el primer déficit del balance comercial de los Estados Unidos desde fines del siglo xIx. Se sumó a esto una fuerte presión especulativa contra el dólar: la salida de capitales de corto plazo superó los us $\$ 20$ mil millones. Como contraparticla, Alemania y Japón volvieron a registrar fuertes superávit. Las tensiones en los pagos internacionales y los mercados cambiarios resultaron totalmente inmanejables. Las medidas que se habían aplicado hasta entonces, resultaban inoperantes. Ante la magnitud del desajuste, las revalua. ciones modestas de las paridades de las monedas superavitarias o los acuerdos de asistencia recíproca entre las autoridades monetarias constituían meros paliativos. Además, era inadmisible provocar el ajuste mediante un aumento drástico cle la tasa de interés en los Estados Unidos y una política fiscal restrictiva. Sus efectos internos sobre la producción .y el empleo y su repercusión recesiva sobre el resto del sistema trilateral, hubieran sido desastrosos. Los países superavitarios, Alemania en primer término, se negaban, a su vez, a revaluar drásticamente sus monedas, liberar unilateralmente sus inportaciones y a promover, por estas vías, la recuperación del balance comercial de los Estados Unidos. El déficit norteamericano era tan descomunal y la acumulación de dólares en el resto del mundo ${ }^{3}$ de tal proporción, que ningún paliativo podía producir efectos apreciables en los pagos internacionales $y$ en el comportamiento de los mexcados cambiarios.

En el marco de una situación insostenible, los Estados Unidos abandonaron su politica de sostenimiento de la convertibilidad del dólar, provocaron un cambio drástico en las reglas del juego y recuperaron su libertad de maniobra en el manejo de sus pagos externos. Las otras medidas de presión sobre el resto del bloque de paises industriales que simultáneamente, en agosto de 1971, aplicó la Administración Nixon, activaron las negociaciones dentro del sistema trilateral. Los Acuerdos del Smithsonian de fines de 1971 consumaron una sustancial modificación de las paridades de las principales monedas, permitieron un margen de fluctuación más amplio en torno de las paridades establecidas y adquirieron un valor simbólico: por primera vez, en la historia económica de los principales paises, un ajuste de paridades surgia de un acuerdo internacional. Las medidas de $197 \mathrm{l}$. preservaron las ya magras reservas de oro y divisas norteamericanas y mejoraron, en alguna medida, la posición competitiva de los Estados Unidos, facilitando una mejora de sus pagos externos. Pero las tensiones en. los mercados cambiarios se mantu-

${ }^{3}$ En la actualidad se estima que las tenencias de activos de corto plazo en dólares en el resto del mundo asciende a us\$ $400 \mathrm{mil}$ millones. 
vieron durante todo el año 1972 y hasta bien entrado 1973. Luego del cierre temporario de los mercados cambiarios en marzo de este último año, se abandonó definitivamente el régimen de paridades establecido en Bretton Woods y generalizó la flotación del dólar y las principales monedas. Varios miembros de la Comunidad Económica Europea resolvieron flotar sus monedas frente al dólar y mantener entre ellas el margen máximo de fluctuación del 2.25\%.

Desde fines de 1973, el drástico aumento de los precios del petróleo introdujo un nuevo factor de desequilibrio en los pagos internacionales. Dada la escasa capacidad de los miembros de la OPEP de absorber a corto plazo un fuerte incremento de recursos reales, aquel aumento de divisas provocó un espectacular aumento de sus reservas internacionales. En poco tiempo, Alemania y Japón lograron acrecentar el superávit de otras cuentas de sus pagos externos y recuperar su tradicional posición superavitaria. De este modo, el déficit de pagos del resto del mundo frente a la OPEP se concentró en las cuentas corrientes de los Estados Unidos, otros paises industriales $y$ varios paises en desarrollo. De este modo, se profundizaron los desequilibrios preexistentes en los pagos internacionales.

El sistema financiero internacional reveló una considerable aptitud para responder inmediatamente al nuevo desafio. El reciclaje de los petrodólares hacia los paises importadores de petróleo, incluyendo a algunas economías en desarrollo, facilitó el proceso de ajuste del nuevo desequilibrio. El aumento de la deuda externa permitió mantener el nivel de las reservas internacionales de los países deficitarios en petróleo y evitar la adopción de medidas drásticas de restricción interna, para reducir las importaciones del hidrocarburo y el nivel de la actividad económica. Los mercados de euromonedas recibieron un sustancial aporte de fondos originados en los miembros de la OPEP.

En 1974, el aumento de los precios del petróleo representó una transferencia de recursos financieros, desde el resto del mundo hacia los miembros de la OPEP, equivalentes al $1.5 \%$ del producto mundial. Provocó, además, un incremento del nivel de precios de los países industriales de alrededor del 2\%. Entre 1974 y 1977, el superávit de la cuenta corriente de los miembros de la OPEP ascendió a us $\$ 180$ mil millones. A partir de 1974, el eficaz reciclaje de los excedentes financieros de la OPEP, el progresivo deterioro de los precios reales del petróleo y la menor expansión de las importaciones de combustible en el mundo industrializado, contribuyeron a debilitar el papel de los nuevos precios del hidrocarburo, como factor autónomo y significativo en el comportamiento de los pagos internacionales. Después de su impacto inicial, el aumento dejó de jugar como factor autónomo de la inflación $y^{\prime}$ de la distribución internacional del ingreso. Antes bien, la pérdida progresiva del precio real del pe- 
tróleo revirtió parcialmente las consecuencias de aumento inicial. Los gobiernos de los principales países industriales responsabilizaron a la OPEe por la aceleración de la inflación, el receso y los mayores desequilibrios de los pagos internacionales. Recientemente, en esos mismos paises se ha llegado a reconocer que el aumento de los precios del petróleo era indispensable para rectificar las distorsiones en las polfticas energéticas gestadas, durante varias décadas, por precios excesivamente bajos del hidrocarburo. Por otra parte, el comportamiento' de la economía internacional desde 1974, ha demostrado que la inflación, el desempleo y los desequilibrios de pagos tienen raíces más profundas que la politica de precios de la OPEP.

El creciente desequilibrio de los pagos dentro del sistema trilateral, las presiones especulativas $y$, a partir de 1973 , el aumento de los precios del petroleo, impidieron que los Acuerdos del Smithsonian produjeran el crecimiento ordenado de la liquidez internacional y un comportamiento razonable de los mercauos camblarios. A principios de 1973 se abandonaron definitivamente das reglas del juego del sistema monetario establecidas en Bretton Woods y las principales monedas, incluyendo el clólar, comenzaron a cotizarse bajo el régimen de flotación. El Acuerdo de Jamaica de enero de 1976 marcó el límite del proceso de reforma del sistema monetar1o internacional, iniciado en la década de 1960. Se aceptó el régimen de flotación, se asumió el compromiso de no manipulax los tipos de cambio para obtener ventajas competitivas desleales y se acordó la eliminación del oro como activo de reserva internacional.

Las modificaciones en el funcionamiento del sistema monetario internacional tuvieron repercusiones trascendentes en el funcionamiento del orden mundial. Para los Estados Uniclos, el cambio de Las reglas del juego permitió alcanzar tres objetivos simultáneos. Primero, aislar el endeudamiento externo de corto plazo de las magras reservas de oro. Segundo, desvincular el proceso de ajuste de la administración de la demanda interna; desde da flotación en adelante, el ajuste se realizaria por la modificación del tipo de cambio. Tercero, devaluar el dólar y mejorar su posición competitiva, particularmente, frente a Alemania y Japón.

\section{Limites del régimen de flotación y la depreciación del dólar}

En 1977, el balance de comercio de los Estados Unidos registró un deficit comercial, sin precedentes, de us $\$ 30$ mil millones. El incremento de las: importaciones de petróleo y el crecimiento de la demanda interna, relativamente más fuerte que en el resto del mundo industrializado, contribuyeron a ese resultado. En 1978 se prevé un incremento del déficit comercial. El superávit en los otros rubros de 
la cuenta corriente, compensó en parte el délicit comercial. Sin embargo, en 1978, el déficit norteamericano en cuenta corriente alcanzó a casi us $\$ 18 \mathrm{mil}$ millones. Alemania y Japón volvieron a registrar fuertes superávit en cuenta corriente: us\$2.3 mil millones y us\$10 mil millones, respectivamente. Suiza, a su vez, registró un superávit superior a los us\$ 3 mil millones.

Estos desequilibrios en los pagos corrientes fueron agravados por los movimientos especulativos de capitales, dando lugar a un fuerte incremento del endeudamiento de los Estados Unidos a corto plazo y a fuertes modificaciones de las cotizaciones de las principales monedas. La sensible depreciación del dólar frente al yen, el marco alemán y el franco suizo, ha sido el fenómeno dominante de los mercados cambiarios en los últimos meses de 1977 y los primeros de 1978 .

La ambivalencia de la Administración Carter sobre la prioridad de los objetivos empleo y estabilidad, la ha hlevado a adoptar politicas fiscales y monetarias contradictorias. Desde la perspectiva de los enfoques conservadores que predominan en Europa, la ausencia de un enfrentamiento explícito a da inflación mediante los instrumentos tradicionales (restricción fiscal y monetaria, contracción de la demanda y más desempleo) contribuye a intensilicar las presiones especulativas contra el dólar. P'ero es difícil que, con los resultados alcanzados hasta ahora, el enloque conservador cobre una mayor influencia en los Estaclos Unidos. Las politicas ortodoxas han perdido credibilidad y prestigio. Por otra parte, el déficit en cuenta corriente de los Estados Unidos no representa más del $1 \%$ ó $1.5 \%$ del producto interno $y$, dada su forma de financiamiento, no impone una restricción de la liquidez y la demanda interna. Al mismo tiempo, dentro de las nuevas reglas clel juego, los Estados Unidos fortalecieron su posición negociadora dentro del sistema trilateral, La "tolerancia benigna" con que los Estados Unidos observan la persistente depreciación del dólar frente a las principales monedas, refleja varias cosas. En primer lugar, la despreocupación de un pais fuertemente deudor a corto plazo por la pérdida de valor real de sus deudas en virtud de la inflación internacional. En cambio, los créditos de los Estados Unidos frente al resto del mundo son, en lo fundamental, activos reales (inversiones de las corporaciones norteamericanas) que mantienen, o aun acrecientan, su valor frente al proceso inflacionario. En segundo lugar, al permitir la depreciación del dólar, los Estados Unidos transfieren la responsabilidad del proceso de ajuste a los países superavitarios, fundamentalmente, a Alemania y Japón. Se trata, en verdacl, de una situación singular. El principal activo de reserva internacional se deprecia continuadamente y la potencia central del sistema trilateral, que emite la moneda de reserva, conserva su posición dominante. Los Estados Uni- 
dos han aprendido, señala Samuelson ${ }^{4}$, que es un error equiparar la "grandeza nacional" con una moneda fuerte. Recuérdese, por ejemplo, los problemas que enfrentaron Inglaterra, en 1925, y Francia, en la década de 1930, por confundir ambas cosas. En el mismo artículo, Samueison denuncia a los "gnomos europeos" que pretenden el sacrificio norteamericano de altas tasas de interés y otras medidas recesivas, ante el altar de la "defensa del valor del dólar". Es obvio que, por lo menos a corto plazo, los Estados Unidos no tienen un interés real en clefender la paridad del dólar. Inclusive, la remisión de utilidades de las corporaciones norteamericanas, que operan en países cuyas monedas se aprecian en relación al dólar, se incrementa pari passu con esa modificación de los tipos de cambio. Además, en la medida en que la expansión de las subsidiarias norteamericanas se financie con recursos descle fuera de los Estados Unidos, poco puede importarles la depreciación del dólar. En realidad, sólo una visión insensata del proceso de ajuste puede propiciar el aumento de las tasas de interés y la contracción de la demanda en los Estados Unidos. Esto tendria consecuencias desastrosas sobre el nivel de producción y empleo en todo el sistema trilateral. Otra vez, la heterodoxia norteamericana está sirviendo a los intereses clel mundo desarrollado mucho mejor que la visión de los banqueros centrales y otros voceros conservadores de Europa.

La despreocupación norteamericana por la depreciación del dólar tiene, sin embargo, algunos límites. En primer lugar, porque, pese al bajo coeficiente de importaciones, la devaluación estimula ciertas presiones inflacionarias. En el caso del petróleo, como los precios están fijados en dólares, la depreciación de la moneda norteamericana no ha aumentado los precios domésticos del combustible. Pero en otros rubros, los incrementos de los precios en dólares de las importaciones, se traslada a los precios internos, en parte, por su repercusión en la producción similar producida localmente. Por ejemplo, en la última alza del acero, por parte de las principales empresas norteamericanas, influyó el aumento de precios del acero importado. Por otra parte, el impacto de la depreciación del dólar sobre la posición competitiva de los Estados Unidos es más débil de lo que indica la modificación de los precios internos vis a vis los internacionales. Factores distintos al precio, tales como la calidad, seguridad de entrega, servicios de mantenimiento, desarrollo de nuevos productos, origen de las maquinarias y tecnologías ya existentes, debilitan el efecto de la modificación de los precios relativos sobre la mejora de Ia posición competitiva de los Estados Unidos. Por otra parte, las modificaciones de cotizaciones son erráticas y esto no favorece la adopción de decisiones que tienen su efecto sobre el largo plazo. Es-

- P. A. Samuelson: Dollar essentials. Newsweek, enero 23, 1978. 
tos factores contribuyen a explicar el mantenimiento de las corrientes exportadoras de países como Alemania y Japón, cuyas monedas se han apreciado significativamente con respecto al dólar. La modificación de cotizaciones ha contribuido a compensar las distintas tasas de inflación entre los países industriales y, en cierta medida, a impedir el aumento de los desequilibrios de pagos. Pero constituy'e apenas un instrumento de ajuste cuyo impacto está condicionado por la administración de Ia demanda interna y el manejo del conjunto de instrumentos de la política económica.

La depreciación del dólar plantea otros problemas adicionales a los Estados Unidos. En el caso del petróleo, los miembros de la optep observan con creciente alarma la disminución del poder adquisitivo de sus exportaciones en términos de monedas distintas del dólar. Esto puede influir en la cotización del petróleo y las políticas de asignación de excedentes financieros. En los últimos meses los paises petroleros superavitarios han tendido a preferir colocaciones fuera del dólar.

Los Estados Unidos han recuperado libertad de maniobra con la flotación, pero conservan una responsabilidad fundamental en el funcionamiento del sistema trilateral. Una depreciación continuada del dólar y la presión de las exportaciones norteamericanas en el resto del mundo industrializado, pueden intensificar las presiones proteccionistas, que ya son muy fuertes. Los Estados Unidos han desempeñado un papel fundamental en la formación del sistema trilateral a través de sus corporaciones y sus bancos. Grandes intereses de los Estados Unidos están comprometidos con el funcionamiento ordenado y la expansión del sistema. En la medida en que la depreciación del dólar genere perturbaciones severas, los propios intereses norteamericanos resultarán afectados. Esto refleja la estrecha interdependencia existente dentro del mundo industrializado.

\section{Transformación de la posición internacional de las economias centrales}

El origen de los desequilibrios en los pagos internacionales no puede atribuirse sólo a las tendencias de la coyuntura o a la incidencia de los déficit energéticos: Simultáneamente con tales factores, ciertas tendencias de largo plazo contribuyen a modificar la posición de las principales economías industrializadas dentro del sistema trilateral y de ia economía mundial. En el caso de los Estados Unidos, el cambio de posición internacional no se agota con el debilitamiento de su gravitación relativa. Es necesario observar, también, las transformaciones que está experimentando la estructura de su balance de pagos. A este respecto, conviene destacar algunos hechos principales.

Se observa, por una parte, que el mercado internacional de bie- 
nes industriales sigue creciendo más que las exportaciones norteamericanas. Consecuentemente, las exportaciones de manufacturas desde los Estados Unidos continúan perdiendo participación en el comercio mundial de bienes industriales. A fines de la década de 1950, las exportaciones norteamericanas representaban el $26 \%$ de las exportaciones mundiales de manufacturas; a principios de la década de 1970, la participación había caido al 20\%. Como contrapartida, se observa un persistente crecimiento clel saldo positivo de las transacciones en invisibles $y$, principalmente, del ingreso de utilidades por las operaciones de las corporaciones norteamericanas en el resto del mundo. Tales utilidades superan actualmente los US\$10 mil millones anuales. Entre 1975 y 1977 , el superávit de la cuenta de servicios $y$ transferencias privadas aumentó en $130 \%$, para alcanzar en este último año cerca de us\$ 1.5 mil millones. Las tendencias apuntadas han venido prevaleciendo en los últimos lustros y es probable que continúen operando en el futuro previsible. En este caso, se profundizarian los cambios que viene experimentando la economia norteamericana dentro del sistema internacional. Ella afirmaria su posición como exportadora de servicios y de capitales hacia el resto del mundo.

La profundización de ese cambio parece factible en la medida que la expansión de la demanda interna en los Estados Unidos permita alcanzar altos niveles de crecimiento de la producción y el empleo. En este contexto, parece factible la reasignación de recursos internos y el desplazamiento de mano de obra desde las actividades sometidas a la competencia de las importaciones y la aceptación de un déficit persistente en las transacciones comerciales. En tales condiciones, el crecimiento de la productividad, las ganancias y los salarios permitirían el desplazamiento de recursos hacia las áreas de más alta productividad, orientadas al mercado interno y a la exportación de manufacturas y servicios con tecnologías de vanguardia. En una situación de este tipo, sumada a la reducción y control del déficit energético, parece posible la persistencia de un déficit moderado en el balance de comercio de los Estados Unidos. El superávit en la cuenta de servicios $y$ transferencias privadas permitiria mantener en equilibrio los pagos externos y generar un excedente para las inversiones en el resto del mundo. Pero, en el marco de políticas monetaristas, lento ritmo de crecimiento y altas tasas de desempleo, parece inevitable que las presiones proteccionistas interrumpan esos cambios en la posición externa de la economía norteamericana. Esto debilitaria el crecimiento del comercio y del movimiento internacional de capitales.

En los casos de Alemania y Japón, la eliminación de su cuantioso y persistente superávit en cuenta corriente plantea dos problemas principales. El primero, referido a la administración de la demanda 
y la determinación del nivel de actividad. El segundo, vinculado a 1a utilización del ahorro. Desde el fin de la Segunda Guerra Mundial, aquellos dos países han utilizado el excedente de sus pagos corrientes como un instrumento importante de la expansión de la demanda interna, la producción y' el empleo. El excedente en los pagos externos, como componente importante del ahorro, fue utilizado para expandir la posición de reservas y la liquidez internas y, también, para financiar las inversiones de capital en el exterior. En la medida en que un mayor equilibrio de los pagos internacionales impone la eliminación de los superávit de Alemania y Japón necesaria la adopción de cambios importantes en las políticas económicas de estos dos paises. A saber, un mayor énfasis en la expansión del gasto interno como determinante de la producción y el empleo $y$, consecuentemente, una disminución del ahorro gestado en las transacciones internacionales. Como en el caso de los Estados Unidos, estos cambios imponen el abandono de las politicas ortódoxas orientadas a combatir la inflación mediante el desempleo y la reducción de salarios. Parece evidente que los principales países no podrán compatibilizar los objetivos externos e internos de sus políticas económicas, fuera del marco de transformaciones sociales y políticas internas referidas a la distribución del ingreso $y$ la asignación de recursos.

Los desequilibrios cle pagos dentro del sistema trilateral más é] déficit del sistema con algunos miembros de la OPEP, podrían, en principio, ser eliminados por otra vía. A saber, un fuerte superávit. de los países miembros del sistema con el resto del mundo: los paises en desarrollo y las economias socialistas. O sea, reproducir, en una escala ampliacla, el papel que clesempeñó la: periferia en el funcionamiento del sistema multilaterai de comercio y pagos hasta las visperas de la Primera Guerra Mundlial. Pero esto no parece posible por varias razones.

En primer lugar, porque los paises en desarrollo constituyen hoy un componente marginal -como mercado y fuente de abastecimiento de productos primarios- dentro de los intereses fundamentales del sistema trilateral. Una drástica expansión de la tránsferencia de rècursos, esto es, del superávit en las transacciones corrientes del centro con la periferia, requiere un fuerte incremento de las importaciones del centro. Esto es indispensable para generar capacidad de pagos en la periferia destinada a la importación de bienes y al pago de los servicios de ias crecientes inversiones de capital que el proceso llevaria implícito. Dadas las tendencias imperantes en el desarrollo de los países industriales, no cabe prever un sustancial aumento de

- O su dismintución hasta niveles compatibles con èl funcionamiento del sistema. 
las importaciones desde las economias en desarrollo. Las importaciones de productos primarios continúan atrapadas por las mismas tendencias que prevalecen desde el fin de la Segunda Guerra Mundial. En relación a las importaciones de manufacturas, están directamente ligadas al llamado redespliegue de actividades manufactureras desde los países industriales hacia las economias en desarrollo. Pero este redespliegue, como lo revelan das actuales presiones proteccionistas, depende del nivel de ocupación en las economías centrales. En la medida en que prevalezcan las tendencias actuales de alto desempleo y sostenidas presiones inflacionarias, no se produciría un incremento sustancial en las exportaciones de manufacturas desde la periferia a los centros industriales. Nuevamente, las políticas ortodoxas dificultan el proceso de ajuste de los pagos internacionales y la expansión del comercio y el movimiento internacional de capitales. El incremento de la deuda externa de la periferia es una solución transitoria. A largo plazo, la capacidad de endeudamiento está condicionada por el comportamiento de su capacidad de pagos externos. Brasil, México y otros países en desarrollo han apelado en los últimos años a los mercados privados de capitales y su deuda externa ha creciclo sustancialmente. La situación es manejable siempre $y^{\prime}$ cuando aumenten las exportaciones de bienes $y^{\prime}$ servicios de los paises deudores, limitadas actualmente por el bajo nivel de actividad y de las importaciones de los países industriales.

En segundo lugar, porque no cabe esperar un incremento sustancial de superávit de los paises industriales con las economías socialistas. Esta limitación está dada por la debilidad de las importaciones de este origen en aquellos países y porque, dada esa limitación, no puede preverse un financiamiento externo cuantioso del desarrollo de las economías socialistas.

$\mathrm{Si}$ es cierto que el resto del mundo sólo puede desempeñar un papel marginal en el proceso de ajuste de los pagos internacionales del sistema trilateral, entonces las soluciones están dentro de las propias fronteras del sistema. De este modo, la política de ajuste externo aparece cada vez más vinculada a la determinación del empleo y a la concertación de políticas entre los principales países. El sistema trilateral creció desde el fin de la Segunda Guerra Mundial merced al desequilibrio de los pagos internacionales $y$, en primer lugar, al déficit norteamericano. Desde principios de la década de 1970, no puede seguir creciendo con desequilibrios que amenazan la viabilidad del sistema a largo plazo. $\mathrm{La}$ vinculación cada vez más estrecha entre las políticas internas de los principales países y los pagos internacionales, es uno de los rasgos dominantes de la nueva situación. En este contexto, debe insistirse en el hecho que la superación de los desequilibrios en el sistema monetario internacional depende, fundamentalmente, de la superación de los dilemas en que está actualmente 
atrapada la política económica de los paises centrales. Parece, en efecto, imposible recuperar un comportamiento ordenado de los pagos internacionales hasta que los principales paises reanuden un crecimiento sostenido de la producción y el comercio internacional recupere fuertes tasas de expansión.

\section{Dilemas y frustraciones de la politica económica en los paises desarrollados}

Desde fines de la década de 1960 hasta principios de la actual, el sistema trilateral registró un fuerte crecimiento de la producción y el empleo y presiones inflacionarias en ascenso. En 1973, año de culminación de ese proceso, el producto agregado del mundo industrializado creció en un $6 \%$ y los precios al consumidor aumentaron en $10 \%$. Bajo el estímulo de la fuerte expansión de la demanda clentro del sistema trilateral el comercio mundial creció a un ritino sin precedentes históricos $-12 \%$, pero se agudizaron los desequilibrios en los pagos internacionales y las turbulencias en los mercados cambiarios. Entre 1972 y 1973, la fuerte expansión de la demanda empujó los precios al alza, aun cuando no podría decirse que el sistema había llegado al límite de utilización de su capacidad productiva. Pero en el marco de la expansión, se agudizaron las expectativas inflacionarias. Coincidentemente, se produjo un alza brusca de precios de alimentos y materias primas debido a insuficiencias transitorias de oferta, por el fracaso de la producción agrícola en algunos paises, y a otros factores. A fines de 1973, el drástico aumento de los precios del petróleo terminó de configurar la explosión inflacionaria dentro del mundo industrializado.

La nueva situación provocó un cambio drástico de la politica cconómica en los principales países. El control de la inflación se convirtió en la preocupación cominante y se generalizaron las politicas de restricción de la liquidez y de la demanda para disminuir el nivel de la actividad productiva. Las inciertas perspectivas de los consumidores, la liquidación de existencias y la caída en la acumulación de capital, provocaron una contracción generalizada de la demanda. El impacto de las políticas recesivas fue realmente notable en 1974 y 1975. Prácticamente, por primera vez desde el fin de la Segunda Guerra Mundial, se produjo una caída de Ia producción en el mundo industrializado. Entre 1973 y 1975, el producto industrial cayó en $15 \%$ en los Estados Unidos y otro tanto en el resto del sistema trilateral. El desempleo aumentó drásticamente, hasta niveles desconocidos desde las vísperas de la última guerra mundial. En 1975 superó, en los Estados Unidos, al $18 \%$ y al $5 \%$ en Ios otros países avanzados. En ese año, dentro del sistema trilateral los desocupados ascendían a más de 15 millones. La brusca contracción de la activi- 
dad económica y la productividad, mientras persistían los fuertes aumentos de salarios nominales de la fase de expansión, provocó un drástico aumento de los costos unitarios del trabajo y un nuevo salto de la tasa de inflación. En los países miembros de la OECD, el aumento de precios al consumiclor en 1974 y 1975 alcanzó al 19\% anual. El sistema trilateral enfrentó en esos años una situación sin precedentes: contracción de la producción y el empleo e insólitos aumentos de precios. El comercio internacional registró el impacto del receso en los países industriales. Entre 1960 y 1973, el comercio dentro del sistema trilateral, que representa cerca del $60 \%$ del comercio mundial, aumentó a una tasa del $12 \%$ anual. Entre 1973 y 1977 , la tasa declinó al $2 \%$ anual. La tendencia se generalizó al conjunto de las transacciones internacionales.

Los indicadores mencionados bastan para configurar la nueva situación al promediar la década de 1970 . En ese contexto, las politicas de signo keynesiano perdieron capacidad de compatibilizar el pleno empleo con una cstabilidad razonable de precios. La administración de la demanda agregada a través de la oferta monetaria y la política fiscal, genera tensiones insoportables antes de llegar a una posición de pleno empleo. Los cambios estructurales y el reparto del poder, cientro de las economías integrantes del sistema trilateral, no pueden ser regulados con herramientas de políticas macroeconómicas, como las utilizadas por el keynesianismo. Guando existe una concentración del poder económico en empresas oligopólicas, en sindicatos de fuerte poder negociador y en un sector público que absorbe proporciones crecientes de los recursos disponibles, no es posible, por medio de aquellas políticas, regular el empleo y la distribución del ingreso. Por otra parte, las rigideces de oferta en ciertos puntos críticos del sistema provoca alzas de precios, aun cuando, globalmente, no sc utilice plenamente la capacidad productiva existente. Por ejemplo, la escasez de oferta de energía, la baja productividad de los servicios de salud, el alto costo de la tierra para la construcción de viviendas y la rigidez a corto plazo de la oferta de ciertos alimentos, tienden a provocar alzas sectoriales de precios que se transmiten al nivel general de precios. Recuérdese que esos cuatro rubros (salud, alimentos, vivienda y energía) constituyen, por sí solos, la mayor parte del gasto de las familias ${ }^{6}$.

- En los Estados Unidos el 80\%. Tom Wicker: Big foltr mflation. The New York Times, jul:o 26, 1977. Es interesante observar los puntos de contacto de este tipo de enfoque con la escuela estructuralista latinoamericana. En ésta se conficre tumbien importancia a las restricciones de oferta como fuente principal de las presiones inflacionarias. La dif:cultad de reasignar recursos para eli. minar tales restricciones y modificar los precios relativos sin cambios sustanciales en el nivel general de precios constituyen, entonces, obstáculos fundamentales para las políticas de estabilización. En este contexto, los aumentos de sala- 
La composición de la fuerza de trabajo impone, a su vez, fuertes limitaciones a la regulación de los salarios a través del nivel de empleo. En los Estados Unidos, la población trabajadora blanca adulta proporciona la menor parte de las horas trabajaclas. En ella la talsa de desempleo actual es menor del $4 \%$, mientras que asciende al $6.2 \%$ en las mujeres blancas, al $11.1 \%$ en los negros adultos, al $15 \%$ en los jóvenes blancos y al $39.5 \%$ en los negros ${ }^{7}$. La expansión de la demanda de mano de obra, cuando crece la producción se plantea predominantemente en los trabajadores blancos adultos, que constituyen la oferta de trabajo más calificada y de más alto nivel de sindicalización. Estos aumentos de salarios tienden a generalizarse en toda la fuerza de trabajo. En tales condiciones, la presión cle los salarios sobre los costos se produce mucho antes que, en la mayor parte de la fuerza de trabajo, se hayan alcanzado niveles satisfactorios de empleo. En los Estados Unidos la situación tiende a agravarse: persiste la modificación en la composición de la fuerza de trabajo, con el continuado incremento del peso relativo de los sectores "marginales". En tales condiciones, las politicas de restricción de demanda agravan el desempleo y la marginalidad del grueso de la población activa.

A su vez, la generalización de la indisación ha introducido nueva r:gidez en la estructura de precios y la distribución clel ingreso en los paises desarrollados. Contribuye a generalizar las alzas sectoriales cle precios a tocio el sistema. Dificulta, también, la reasignación de recursos y la redistribución de recursos necesarias para eliminar las rigideces de oferta en los puntos críticos del aparato productivo. Amparados en el régimen de indisación, los sectores de may'or poder relativo dentro de las economias inclustriales, pueden resistir Jas pérdidas cle ingresos implícitas en el aumento de los precios del petróleo o en la caída de productividad provocada por el receso económico. Dentro de las estructuras oligopólicas que predominan en los principales mercados y del régimen de precios administrados, las empresas tienen posibilidad de manipular sus márgenes de ganancia.

En este contexto, el keynesianismo, en sus versiones recientes $y$ más sofisticadas, ha procurado ampliar el área de los instrumentos de acción, inciuyendo las medidas para la administración de la demanda, el mejor funcionamiento de los mercados, las politicas de

\footnotetext{
rios, la expansión de la liquidez y los ajustes cambiarios aparecen como mecanismos de propagación de alza de precios que tienen su origen en aquellas rigideces estructurales de la oferta. Como en el enfoque comentado, la escuela estructuralista latinomericana destaca las limitaciones de la politica monetaria y de la disminución del nivel de la actividad, el empleo y los salarios como instrumentos eficaces en la lucha antiinflacionaria.

7 L. Thurow - Inequality, inflation and growth in the American economy. The Economist, diciembre 22, 1977.
} 
ingresos en términos de pautas orientadoras sobre el comportamiento de precios y salarios y, también, la fijación de metas cuantitativas de la oferta monetarias. El éxito de estas versiones más amplias del enfoque keynesiano ha sido, hasta ahora, reducido.

No es extraño que, ante el fracaso de las politicas prevalecientes y la explosión inflacionaria, hayan vuelto a reflotar Ios enfoques ortodoxos que prevalecieron hasta principios de la década de $1930 . \mathrm{E}$ ? argumento básico del enfoque ortodoxo es que, más allá de c:ertos niveles de empleo, la demanda de aumentos cle salarios tiende a exceder los incrementos de productiviclad y a reducir las ganancias. De aqui surgen dos consecuencias principales: el aumento de los costos unitarios del trabajo y el desaliento a la inversión privada. La inflación y el estancamiento están ligados, en ese enfoque, con el comportamiento del empleo y los salarios. El canje desempleo-inflación propuesto inicialmente, a fines de la década de 1950, en las curvas de Philips, suministró evidencia empírica para la propuesta ortodoxa.

El instrumento dominante de acción del enfoque ortodoxo es la política monetaria. Su objetivo es restringir la liquidez para no permitir que las presiones sectoriales por la distribución del ingreso se reflejen en el nivel de precios. De este modo, bajo el liderazgo del Bundesbank, la Reserva Federal y el Banco Nacional Suizo, los banqueros centrales se han convertido en gestores principales de la política económica dentro del sistema trilateral. Hasta ahora, la aceptabilidad de la política monetarista ha tenido dos puntos de apoyo importantes. Primero, la preocupación generalizada en todos los sectores sociales por el problema de la inflación. En la opinión pública de los países industriales, la inflación parece preocupar, todavia, más que el desempleo. Segundo, el atractivo que la teoría cuantitativa de la moneda ha ejercido tradicionalmente por su sencillez explicativa de la determinación del nivel de precios.

Sin embargo, las políticas monetaristas adolecen del mismo defecto instrumental que las de signo keynesiana: pretender operar con herramientas macroeconómicas en un sistema que, por su complejidad, no puede ser regulado con ese tipo de instrumentos. Por otra parte, las politicas ortodoxas tienen pésimos antecedentes. Las medidas de reducción de salarios, presupuestos equilibrados y restricción de la oferta monetaria tuvieron en el pasado un elevado costo y revelaron su incapacidad de superar las crisis del sistema. Recuérdese la experiencia durante los primeros años de la década de 1930 .

Pero el enfoque ortodoxo plantea problemas en un nivel más profundo referido a la naturaleza misma del proceso de crecimiento $y$, consecuentemente, a la estrategia necesaria para promoverlo. En ese enfoque, el ritmo y la continuidad del desarrollo econórnico depende

- OECD: Towards full employment and price stability. Paris, 1977. 
de la inversión privada. Esta opera como factor de autosostenimiento de aumento de la demanda y, al mismo tiempo, de expansión de la capacidad productiva. La confianza de los inversores es, por lo tanto, un elemento fundamental para determinar el nivel de inversiones, el crecimiento y el empleo. Si, por el comportamiento de los salarios y la productividad, la tasa de ganancias no satisface las expectativas de los empresarios, la inversión disminuirá y se orientará, como en la experiencia reciente, a sustituir mano de obra más que a expandir la capacidad productiva y la demanda de empleo. La inversión privada estaría acosada actualmente por incertidumbre generada, principalmente, en el proceso inflacionario, pero, también, en las crecientes regulaciones gubernamentales como las referidas al control de la contaminación ${ }^{9}$. La incertidumbre se manifiesta en la incidencia del riesgo de la inversión y éste, como un factor adicional del costo, disminuye el número de proyectos capaces de satisfacer los criterios financieros convencionales. La contención de la inflación vía reducción de la participación de los asalariados en el ingreso, el aumento de los beneficios y la disminución de la intervención del Estado, serían por lo tanto, condiciones indispensables para mejorar el clima de confianza y expandir la inversión privada. En este contexto, el aumento de la tasa actual de desempleo, como instrumento de regulación de la distribución del ingreso, sería un costo que debe pagarse para asegurar el crecimiento del sistema a largo plazo, una más eficiente asignación de recursos y mayores niveles de empleo más tarde.

Pero las políticas que se consideran necesarias para crear confianza en el sector privado, tienen un costo intolerable a corto y mediano piazo. En Europa, los teóricos del enfoque ortodoxo insisten en la necesidad de mantener con firmeza las políticas restrictivas para frenar la inflación. Pero admiten que el precio que Europa deberá pagar será un prolongado periodo de crecimiento lento, bajas ganancias y persistencia de las actuales altas de desempleo ${ }^{10}$. En los Estados Unidos, la brecha entre la producción actual y la potencial supera los US\$130 mil millones 11 . Este desperdicio de recursos por la subutilización del potencial productivo disponible triplica el valor cle las importaciones actuales de petróleo de los Estados Unidos.

La propuesta ortodoxa de un crecimiento lento y alto desempleo para frenar la inflación es incompatible con la viabilidad del sistema a largo plazo. Una de las mayores conquistas del capitalismo ha si-

- Alex Greenspan. Investment risk: the new dimension of policy. The Economist. Londres, agosto 6 de 1977.

${ }^{10}$ The new european unity: a conservative war on inflation, Business Week, junio 27,1977 .

It Walter Heller: Productivity and GNP potential. Wall Street Journal, junio 29, 1977. 
do incorporar el creciniento como condición necesaria cle su vigencia a lárgo plazo. Dado el crecimiento de la productividad impulsada por el progreso técnico y la acumulación de capital, la expansión de la demanda y la producción agregadas son indispensables para mantener niveles satisfactorios de empleo. De otro modo, la desocupación crecería persistentemente hasta límites intolerables para la estabilidad del sistema.

Desde el punto de vista del funcionamiento del orden internacional articulado por el sistema trilateral, incluyendo la expansión de las corporaciones transnacionales, el crecimiento de la producción y el empleo es, también, una condición necesaria. La ciesocupación y el bajo nivel de actividad están desencadenando fuertes presiones proteccionistas, originadas en los sindicatos y las ramas inctustriales más afectadas por las importaciones $y$ la debiliclad de la demanda interna. Hasta ahora, los gobiernos de los principales países inclustriales se han resistido sistemáticamente a abandonar las reglas de liberación del comercio gestadas desde el fin de la Ssgunda Guerra Mundial. En los listados Unidos se ha soslayado la presión proteccionista llegando, con algunos paises, a acuerdos "voluncarios" para la regulación de las exportaciones al mercado norteamericano. l'ales los casos de los acuerdos sobre calzado con Coreal $y^{\prime} \mathrm{TV}$ en colores con Japón. En Europa, las presiones proteccionistas son también muy fuertes contra la competencia japonesa y las manufacturas provenientes de paises en desarrollo. l'roductos tales como calzado, vestuario, artículos electrónicos, acero, rodamientos y barcos, han estado sujetos a fuertes reclamos proteccionistas. Además, sobre todo en los Estados Unidos, los sindicatos critican a las inversiones en el exterior de las corporaciones industriales $y$ las responsabilizan del cierre de fuentes de trabajo y el aumento de la competencia de productos importados. La profundización de los problemas del lento crecimiento $y$ el desempleo amenaza al orden económico internacional, dentro del cual se han desenvuelto y expandido las corporaciones transnacionales de los principales países. Este es un resultado contradictorio con uno de los objetivos básicos del enfoque ortodoxo que radica, como en la estrategia de las corporaciones transnacionales, en la asignación de recursos a escala mundial, en el marco de regímenes liberales de comercio y pagos.

La contradicción entre las politicas ortodoxas respaldadas por los grandes intereses económicos de los principales países y las condiciones reales necesarias para su clesarrollo a largo plazo, es uno de los rasgos más notables de la situación actual en los países inclustriales. Un fenómeno igualmente notable es la incapacidad de otros sectores sociales de promover respuestas politicas que transen la puja por la distribución del ingreso y el poder, en el marco de la expansión de la producción, del empleo $y^{y}$ los niveles de vida. Una cosa 
parece cierta: el estancamiento agrava esos conflictos y dificulta la asignación de recursos para eliminar las rigideces de oferta que obstaculizan el crecimiento del sistema.

Los paises industriales se debaten actualmente en la incertidumbre acerca de la naturaleza del proceso de crecimiento con estabilidad de precios a largo plazo. El fracaso de los intentos monetaristas y keynesianos de promover la recuperación sin inflación, bajo el liderazgo de la inversión privada, puede provocar cambios intportantes en las políticas de los países desarroliados. Después de las proposiciones relativas a los límites materiales al crecimiento y de las propuestas de crecimiento cero, se ha generalizado la convicción de que tales límites no existen dentro de plazos históricos significativos. Además, el desarrollo económico continuado es un requisito indispensable para la viabilidad de las sociedades contemporáneas, inclusive en el mundo industrializado. Los límites al desarrollo son, en todo caso, de naturaleza social y politica.

\section{LAS RELACIONES NORTE-SUR EN EL ACTUAL CONTEXTO INTERNACIONAL}

La crisis del sistema trilateral está afectando severamente a la periferia. EI proteccionismo contra productos importados desde los países en desarrollo, el debilitamiento de la demanda y. los precios, han agravado el desequilibrio de pagos de las economias periféricas ligadas al sistema. El comportamiento reciente de la actividad económica en los centros ha contribuido a empeorar el crónico desequilibrio externo de la mayor parte de las economías. en desarrollo. El aumento de los precios del petróleo agravó el problema en algunos casos pero, ese factor, sólo represental el $20 \%$ del incremento del déficit externo de esos paises en los últimos años.

Se ha recordado en las consideraciones anteriores, el clebilitamiento de los vinculos entre el sistema trilateral y ia periferia. Con la cxcepción de Japón, el comercio y otras transucciones con los países en desarrollo ha venido perdiendo importancia relativa para los paises industriales. La considerable expansión de las exportaciones de manufacturas desde las economías en desarrollo más avanzadas no ha logrado revertir las tendencias prevalecientes en el comercio mundial en las últimas décadas. Está, además, amenazada por la generalización de demandas proteccionistas en los países desarrollados. Las tendencias del comercio no han impedido un flujo importante de inversiones privadas directas, particularmente en las actividades industriales vinculadlas al mercado interno $y$, en alguna medida, a las exportaciones desde los paises en desarrollo. Con todo, en términos relativos, las inversiones de las corporaciones transnacionales se han concentrado crecientemente dentro de las propias fronteras del 
sistema trilateral. Es en el campo financiero, a través del acceso de algunos países en desarrollo a los bancos transnacionales y al mercado de euromonedas, donde se ha producido, en los últimos años, el proceso mús significativo de estrechamiento de los vínculos del sistema trilateral con algunas economias que integran la periferia.

Pese a todo, puede reiterarse que la periferia es marginal para los intereses centrales del sistema trilateral. Lo cual no quiere decir que la periferia no siga conservando considerable importancia en el conjunto de aquellos intereses. Baste con recordar los abastecimientos petroleros, la dimensión de las inversiones privadas directas y la deuda de ciertos países en desarrollo. De todos modos, la periferia juega hoy, en el desarrollo de los países industriales, un papel mucho menos importante que el desempeñado durante la fase de expansión del mercado mundial a partir de la segunda mitad del siglo $\mathrm{xIx}^{12}$.

La periferia del sistema trilateral abarca tal multiplicidad de situaciones que sólo una licencia del lenguaje permite ubicar, en la misma categoría, a países tan distintos en sus dimensiones, niveles de desarrollo e inserción internacional. Esta situación, sumada a la marginalidad de esos países dentro del sistema mundial, no impide, sin embargo, que la expresión Tercer Mundo haya adquirido significación en las relaciones internacionales contemporáneas. En ese universo tan complejo y diverso, se han gestado acontecimientos que, en los últimos años, han tenido una fuerte repercusión sobre el sistema trilateral. Las turbulencias políticas de la periferia repercuten en los centros, sobre todo cuando inciden en las relaciones entre las superpotencias. Guando las relaciones de poder entre los Estados Unidos y la Unión Soviética están en juego, los conflictos políticos y militares dentro del Tercer Mundo repercuten severamente en las relaciones internacionales. Recuérdense, solamente, el antiguo conflicto de Vietnam y las tensiones actuales en Africa y el. Medio Oriente. Inclusive, en el ámbito económico, la periferia ha producido acontecimientos que han afectado sensiblemente al sistema trilateral. El aumento de los precios del petróleo, decidido por los miembros de la OPAP, es el acontecimiento más significativo en ese ámbito. Pero no sólo esto. La generalización de politicas de nacionalización de recursos básicos, las nuevas políticas de tratamiento a la inversión extranjera y la transferencia de tecnología, son también procesos que han contribuido a conmover las relaciones tradicionales del sistema trilateral con el Tercer Mundo. El rápido incremento del financiamiento privado de los desequilibrios cle pagos de Brasil, México y otros países en desarrollo ha generado un considerable grado de compromiso de los centros financieros mundiales con esos países.

^ Economia internacional contemporánea, op. cit. Cap. I. 
Para las instituciones financieras vinculadas a esa transferencia de recursos, los vínculos con la periferia, distan de ser marginales dentro de sus operaciones globales. Pero no está de más una breve referencia histórica. Ese tipo de situación no es nueva ni ha alcanzado la gravitación de otros tiempos. Recuérdese, por ejemplo, la dimensión de los créditos del mercado financiero de Londres, concedidos a la Argentina hacia fines del siglo xrx y como, la crisis de pagos de aquel pais en 1890, hizo tambalear al principal mercado financiero de la época.

En los últimos años, otros acontecimientos han contribuido a acrecentar la significación de la periferia para el clesenvolvimiento del sistema trilateral y sus vinculos con el resto del mundo. Por un lado, el inexorable acercamiento entre todas las realidacles nacionales y continentales impuesto por el progreso técnico, particularmen. te el registrado en los medios de transporte y las comunicaciones. Hoy en día, cada conflicto local tiene sus repercusiones internacionales. Por otro, la conciencia creciente de la universalidad de los problemas del género humano y de los vínculos inexorables entre cada hombre y cada país con sus congéneres. En este sentido, los estudios globalistas sobre el destino de la humanidad auspiciados por $\epsilon$ l Club de Roma, las Naciones Unidas, la Fundación Bariloche y otras instituciones, han contribuido a revelar esa dimensión planetaria del destino del hombre y de las relaciones internacionales. Con todas las exageraciones que puedan haber tenido, las especulaciones sobre el supuesto agotamiento de los recursos naturales no renovables, la explosión demográfica en la periferia y la contaminación del medio ambiente, han contribuido a llamar la atención sobre la universalidad e indivisibilidad de los problemas contemporáneos.

Dentro de este nuevo contexto, ese conjunto de paises tan diversos que llamamos Tercer Mundo, produjo una serie de pronunciamientos internacionales significativos. La ofensiva reivindicatoria de los paises en desarrollo dentro de las Naciones Unidas y en otros foros, sobre las iniquidades de las relaciones prevalecientes en el orden internacional, ha dado lugar a importantes replanteos. El Nuevo Orden Económico Intemacional, la Carta de Derechos y Deberes Económicos de los Estados, las conferencias de la UNGTAD, las propusstas del Grupo de Países No Alineados y del Grupo de los 77, constituyen las manifestaciones más importantes de ese replanteo en los vinculos del sistema trilateral con los países en desarrollo. Pese a la diversidad, desarticulación $y$, a veces, conflictos de intereses dentro del Tercer Mundo, los paises que lo componen han operado con considerable coherencia en los foros internacionales. Cierto es que esta actividad ha tenido, hasta ahora, un valor más formal y decla- 
rativo que de real significación en el comportamiento de los principales actores en el orden mundial. Con todo, la insistencia de los reclamos, en un marco internacional realmente conflictivo, contribuye a configurar una situación fluida en las relaciones internacionales $y$ al convencimientó generalizado de que las cosas no pueden seguir del mismo modo. La dimensión planetaria de las relaciones internacionales y de cada experiencia nacional está provocando cambios que alectarán profundamente el comportamiento del sistema mundial. La crisis energética y su dimensión internacional; la vinculación entre las estructuras del subdesarrollo en la periferia y los factores dominantes en el mercado mundial; da preservación del medio ambiente y su dimensión planetaria; la profundiclad de la crisis politica y de los modelos de desarrollo en los mismos paises industriales; la transferencia de los conflictos del Tercer Mundo al sistema mundial, entre otros factores, contribuyen a la aceptación generalizada de que el cambio en las relaciones internacionales es necesario e inevitable.

- Estas tendencias tendrán, sin duda, una gravitación creciente en las relaciones internacionales a mediano y largo plazo. Pero, en el futuro previsible, no cabe esperar cambios fundamentales en el comportamiento del sistema trilateral frente a la periferia. La última instancia negociadora importante, la Conferencia de París cuncluida a principios de 1977, reveló los límites actuales al diálogo Norte-Sur. Esos límites son tres. Primero, el carácter marginal de la periferia dentro de los intereses centrales del sistema trilateral. Segundo, la naturaleza interna, nacional, de los problemas del subdesarrollo de lá mayor parte de los países del Tercer Mundo y la responsabiliclad insoslayable de cadä uno de ellos en la superación de esos problemas. Tercero, el hecho que la transformación de las relaciones de la periferia con el sistema trilateral descanse, primordialmente, en la capacidad de las naciones en desarrollo de adoptar decisiones unilaterales de suficiente racionalidad y eficacia.

'Én otros términos, los problemas del subdesarrollo' no pueden resolverse en el ámbito del diálogo Norte-Sur ni los países del Tercer Mundo pueden formular reclamos al sistema trilateral por decisiones cuya responsabilidad descansa, primariamente, en esos mismos países: Más aun, sólo a partir de decisiones propias de los países en desarirollo cabe esperar respuestas positivas desde el sistema trilateral. La dispersión del poder económico en varios grandes centros de podèr "económico y la presencia de otros centros dentro del grupo de pä́ses socialistas, confieren a los países del Tercer Mundo una libertad de maniobra en el manejo de sus relaciones internacionales, désconocida hasta tiempos recientes. El carácter predominante interno de"los problemas del subdesarrollo, esa permisibilidad del orden 
internacional para nuevas políticas independientes $y$ la creciente complejidad y profundidad de las relaciones internacionales, contribuyen a generar una situación paradojal. Los países del Tercer Mundo están cada vez más ligados al orden internacional y, al mismo tiempo, sus propias decisiones son la clave de su transformación interna y de la revisión de sus relaciones internacionales. En las consideraciones del apartado siguiente se explora la significación de esta paracloja para la América Latina.

Es notable, también, el hecho que, hoy, las decisiones que el sistema trilateral adopte para resolver sus propios problemas de inflación y desempleo, son más importantes que las medidas de cooperación de los paises industriales con las economias en desarrollo. Estas medidas, como lo revela la experiencia, tienen un alcance limitado e insustancial y no cabe esperar, por las razones que se han visto antes, cambios fundamentales en las respuestas autónomas del sistema trilateral frente al Tercer Mundo. En cambio, la recuperación de una alta tasa de crecimiento en los centros, la superación del desempleo y el control de la inflación, son condiciones necesarias para la expansión del comercio internacional, la liberalización del acceso de nuevos productos de la periferia en los mercados trilaterales y el aumento de la transferencia de recursos financieros y tecnología. Desde esta perspectiva puede afirmarse que, más importante que lo que los miembros del sistema trilateral puedan hacer por el Tercer Mundo, es lo que aquellos países puedan hacer por ellos mismos. Es decir, por superar sus problemas actuales de lento crecimiento, desempleo e inflación y, también, por restablecer un orden razonable en sus pagos internacionales, eliminando los fuertes desequilibrios de sus transacciones reciprocas y las consecuentes tensiones sobre el sistema monetario internacional.

\section{LA MAYOR AUTONOMIA POTENCLAL DE AMERICA LATINA}

Desde estas perspectivas debe destacarse que la autonomía potencial de la América Latina frente al mundo externo se ha ampliaclo sustancialmente en los últimos lustros. La capacidacl de aprovechar esa mayor autonomía potencial depende del tamaño de cada país, su nivel de desarrollo y capacidad de acumulación. Depende, también, de los objetivos que cada país se trace y de la eficiencia y respaldo politico de las estrategias orientadas a promover un desarrollo acelerado e independiente. Pero, más alá de esta dimensión "politica" de la cuestión, los cambios en el contexto internacional y en el sistema económico de la mayor parte de los países del área han aumentado su autonomía potencial frente al resto del mundo. 
Esta autonomía potencial ha sido gestada por la concurrencia de varios procesos simultáneos. Los principales son la dispersión del poder económico en la economía mundial, la menor esencialidad de América Latina para los intereses básicos de los Estados Unidos $y^{\prime}$ del conjunto del mundo industrializado y el considerable desarrollo y potencial de acumulación y cambio tecnológico alcanzado en buena parte de la región. Detengámonos brevemente en estas cuestiones.

La dispersión del poder económico dentro del bloque de países industriales y la multiplicación de las fuentes de abastecimiento de tecnologia, bienes de capital y financiamiento, ha ampliado radicalmente la libertad de maniobra externa de los países latinoamericanos. Con todos los problemas que plantea el actual nivel de endeudamiento externo, poca duda cabe que la ampliación del acceso a los mercados financieros internacionales en los últimos años ha fortalecido aquella libertad de maniobra. Otro ejemplo reciente es el acuerdo nuclear brasileño-alemán formalizado psse a la oposición de Ios Estados Unidos.

Por otro lado, gran parte de las cuestiones conflictivas planteadas entre los centros industriales y los países latinoamericanos no son negociables: su solución depende de la racionaliclad, eficacia $y$ decisión política de estos últimos. Por ejemplo, la revisión de las condiciones de incorporación de inversiones y tecnologia extranjera descansa en decisiones de su ámbito interno. Por cierto que, en las condiciones vigentes en algunos países latinoamericanos, suele ser menos conflictivo nacionalizar una empresa extranjera que introducir una reforma impositiva que grave a los grupos internos de altos ingresos.

Por último, dentro de la América Latina, se han producido cambios profundos que contribuyen a aumentar su capacidad potencial de autonomía. Recuérdense el fuerte aumento de la capacidad productiva $y$, en particular, de la base manufacturera incluyendo las industrias básicas. La expansión de la producción de bienes de capital ha elevado sustancialmente el componente interno de la inversión en maquinarias y equipos. EI potencial de ahorro de la región ha aumentado significativamente. La capacidad de administrar recursos es mucho mayor que en el pasado. Un aspecto importante de este proceso es la aptitud para desatar el "paquete" de la inversión privada directa extranjera en sus componentes financieros, tecnológicos y gerenciales. Asimismo, existe hoy mayor capacidad para negociar la compra de tecnología diferenciando aquellos componentes esenciales que deben ser importados de aquellos otros que pueden ser suministrados internamente. Esta capacidad de desatar los paquetes de inversión $y$ tecnológicos es particularmente notable en los países de mayor desarrollo de la región y ha modificado las pautas tradicionales de negociación con las empresas extranjeras y las 
fuentes tradicionales de suministro de recursos externos ${ }^{13}$. Por otra parte, el alto grado de control extranjero del sistema industrial latinoamericano, el peso de la deuda externa y la imitación de pautas de consumo predominantes en los países desarrollados introduce severas limitaciones en el manejo de las relaciones externas. Asimismo, la concentración del ingreso determina perfiles de demanda, en los cuales, las importaciones y la incorporación de tecnología para la producción de bienes destinados a los grupos de altos ingresos, tienen una pesada gravitación. Pese a estas restricciones, tradicionales por otra parte en la América Latina, las transformaciones internas permiten hoy una capacidad de manejo de las relaciones externas desconocidas hasta no hace mucho tiempo. La América Latina ha alcanzado ya un nivel de desarrollo y disponibiliclad de recursos como para enfrentar con éxito, en plazos históricos razonables los problemas básicos del atraso y la pobreza. El ingreso anual por habitante se ubica en torno de los $\$ 00$ dólares, existe un considerable potencial de recursos $y^{\prime}$ capacidad de administrarlos. En todo caso, el hecho de que el $40 \%$ de la población latinoamericana viva $\in$ n condiciones de "grave pobreza" se explica más por Ia desigualdad en la distribución del ingreso que por la insuficiencia de recursos. Recuérdese que el $50 \%$ de la población latinoamericana percibe el $14 \%$ de los ingresos totales, y el. $10 \%$ de la misma, el $44 \%$. La solución de estos problemas no depende, primordialmente, de las respuestas de los paises avanzados frente al Tercer Mundo, sino de "la adopción de profundas reformas sociales, políticas e institucionales en los países en desarrollo" ${ }^{14}$. Es obvio que la transformación interna de los países latinoamericanos no puede lograrse en el ámbito del diálogo Norte-Sur.

Las respuestas de los países desarrollados hacia la América Latina dependerán primordialmente, de las iniciativas que partan desde esca última. Al fin y al cabo, la Decisión 24 del Grupo Andino y la política nuclear argentina durante la década de 1960 y el planteamiento de un nuevo orden económico internacional, no surgieron de propuestas generosas e iluminadas de los principales países, sino de los nuevos planteos surgidos desde el mundo en desarrollo. Se sugiere aquí que el rumbo de las relaciones entre la América Latina y el sistema trilateral depende, fundamentalmente, de las iniciativas latinoamericanas, incluyendo las referidas a la integración. E1 éxito de la programación industrial en el Grupo Andino, la utilización efectiva de los instrumentos de acción del SELA, el entendi-

${ }^{13}$ Puede verse del autor: Tecnología y política económica en América Latina. Paidós, Buenos Aires, 1975.

* W. Leontief: The future of the world economy. Oxford University Press, Nueva York, 1977. 
miento argentino-brasileño sobre la explotación de los recursos energéticos de la cuenca del Paraná, ejemplifican realizaciones esenciales para el desarrollo de los países del área y para la creación de nuevas condiciones en sus relaciones con el sistema trilateral.

En el futuro previsible $y$ desde la perspectiva latinoamericana, no cabe esperar cambios significativos en las respuestas desde el sistema trilateral hacia los problemas fundamentales que confronta la región. Pero cacaso, esta situación es un obstáculo insalvable para la eliminación del subdesarrollo y la pobreza en la América Latina? ¿No tienen los países de la región más solución para sus problemas que una respuesta iluminada y generosa desde los centros del poder mundial? Desde las perspectivas planteadas en este ensayo, la respuesta es clara. La responsabilidad primaria e insustituible descansa en el ámbito interno de cada país en el marco de un contexto internacional que, nunca antes de ahora, presentó tanta permisibilidad para ei desarrollo independiente de los países del área. 